\title{
Homesickness, Locus of Control and Social Support among First-Year Boarding-School Students
}

\author{
Zulkarnain Zulkarnain ${ }^{\mathrm{a}^{*}}$, Debby Anggraini Daulay ${ }^{\mathrm{a}}$, \\ Elvi Andriani Yusuf ${ }^{\text {a }}$, Maya Yasmin ${ }^{\text {a }}$ \\ ${ }^{a}$ Faculty of Psychology, Universitas of Sumatera Utara, Indonesia \\ ^Corresponding author. E-mail: zulkarnain3@usu.ac.id
}

Background. Homesickness is a common experience among students who live in dormitories. Its symptoms may vary and influence students' academic performance, social involvement, and ability to adapt to a new environment.

Objective. To investigate homesickness, locus of control, and social support among first-year boarding-school students.

Design. This study was conducted to first-year students of boardingschool and involved two hundred and twenty-six students, ages 11-13. A quantitative research design was implemented.

Results. There was a significant influence of locus of control and social support on homesickness among first-year students of boarding school. Social support contributed more to reducing homesickness.

Conclusion. This study can help expand the understanding of homesickness among first-year students, which may lead to improved social support from peers and develop students' locus of control.

\section{Keywords:}

homesickness, locus of control, social support, first-year students, boarding school 


\section{Introduction}

Students generally undergo a transition when they are new to an environment. During this period, they tend to perceive the new environment as something strange, bizarre, and outlandish. According to Stroebe, Van Vliet, Hewstone \& Willis (2002), various habitual factors associated with a new environment lead to feelings of distress and irritation. Bonanno (2001) emphasizes that leaving home has many physical, psychological, and emotional effects on an individual. is one of the many negative feelings associated with this effect (Stroebe et al., 2002).

Homesickness has been defined as a feeling of longing for one's home during a period of absence (Stroebe et al., 2002). It includes strong desire, longing, and thought about everything that revolves around the home. Most often, this is as a result of the difficulty associated with adapting to a new environment. Studies have found that homesickness is experienced by all humans, irrespective of their age and environment. One such emotional transition can be seen in students in boarding schools (Fisher, Frazer, \& Murray, 1986).

Thurber (2007) explained that students who live in dormitories tend to experience homesickness more than other categories of students (91\% and $16 \%$, respectively). Watt and Badger (2009) found that, in students with diverse national backgrounds, approximately $40.4 \%$ experienced homesickness. Tartakovsky (2007) stated that students who migrate to other countries to further their education are likely to experience acculturative stress in their first year, most often associated with their longing to visit home again. The acculturative stress tends to increase in their second year, after which it declines in their third and subsequent years. Homesickness also decreases as academic activities progress.

Poylazi and Lopez (2007) explained that homesickness may harm students' academic performance, social involvement, and ability to adapt to their new environment. Stroebe et al. (2002) emphasized that homesickness could also trigger a variety of psychological problems, such as stress and depression.

With respect to human development, students between the ages of 11 and 14 should be encouraged to be independent. Most of students within this age bracket tend to depend emotionally on their parents or older adults (Hurlock, 1999). Borg and Cefai (2014) wrote that the various conditions associated with separating children from their family are quite influential upon their homesickness. This usually occurs because there is a communication gap during this period, compared to when they lived together.

Several factors lead to homesickness. Tognoli (2003) identifies locus of control as one of these. Feist and Feist (2010) describe locus of control as a person's beliefs about whether they can control of their lives. Locus control can be either internal or external. Individuals with an internal locus of control believe that they could easily control everything that happens in life, whereas persons with an external locus of control believe that events they experience are caused by external factors and cannot be controlled by them (Rotter, 1966).

Lefcourt (1976) states that individuals with an internal locus of control envision changes as challenges. They make numerous efforts to minimize stress and its impact on them. Therefore, it could be concluded that internal locus of control 
helps in controlling, reducing, and eliminating the possibility of an adolescent becoming homesick owing to a change in environment.

Individuals who possess an external locus of control, on the other hand, tend to be more passive in adapting to a situation, because they believe that the situation is beyond their control (Rotter, 1966). Tognoli (2003) found that students with an internal locus of control usually experienced a low level of homesickness. Similarly, Ward and Kennedy (1993), showed that those with an external locus of control, usually have a high homesickness level. Tilburg and Vingerhoets (2005) explain that the separation of individuals from home is indirectly related to the loss of support from family, friends, and their friendly environment. In some cases, however, they regain the needed support from their new social environment, thereby reducing their homesickness to the barest minimum. Social support helps these individuals to deal with their various challenges (Sarafino, 2002).

Sarafino (2002) also found that social support is essential in various aspects of life. The unavailability of social support will make an individual feel worthless and isolated. Sarafino (2006) also clarified that social support can come from life partners, family, friends, co-workers, as well as from community organizations. Peer groups play a paramount role in social support, especially in adolescence. Peers can express opinions, acknowledge weaknesses, and help to solve problems (Papalia, Olds, \& Fieldman, 2007).

Buote et al. (2007) explained that making friends with someone of the same age could assist individuals to adjust to a new environment. Rajapaksa and Dundes (2003) found that people who are not satisfied with their social environment displayed traits of homesickness.

\section{Locus of Control and Homesickness}

Homesickness is an emotional reaction that commonly occurs when individuals feel depressed in adapting to a new environment. Symptoms of homesickness may vary: Some people feel depressed, restless, and have trouble sleeping. Most of these symptoms have negative consequences for those who experience them. People who experience homesickness will experience various types of stress that are characterized by feelings of anxiety, loneliness, and discomfort; they may reject conditions in the new environment and they tend to return to the previous environment (Nejad, Pak, \& Zarghar, 2013).

Tilburg and Vingerhoets (2005) explain that homesickness has four aspects: cognitive, physiological, behavioral, and emotional. The cognitive aspect concerns thoughts about home and negative thoughts about the new environment. The physiological aspect is related to physical complaints, sleep disorders, loss of appetite, and fatigue. The behavioral aspect is related to apathy, lethargy, lack of initiative, and little interest in the new environment. The emotional aspect refers to feeling uncomfortable, anxious, and lonely, as well as losing control.

Tognoli (2003) explains that homesickness is related to locus of control. Locus of control is a concept that refers to individual beliefs about the source of control of events that occur in his/her life. Rotter (1966) explains that there are two types of locus of control, namely internal and external. Internal locus of control can be the 
belief that individual efforts and abilities determine events experienced in one's life, whereas external locus of control can be beliefs that events experienced in one's life are predestined.

Individuals who have a low level of homesickness tend to have an internal locus of control (Tognoli, 2003). They tend to make significant efforts to control their environment, and can control difficult situations during the home-school transition. They believe that individual actions can control all events that occur in life. These beliefs may encourage these people to strive to reduce various negative emotions and to overcome uncomfortable psychological conditions.

Breet, Myburgh, and Poggenpoel (2010) explain that individuals with an internal locus of control can effectively manage emotions and stress by using problem-solving strategies, whereas those with an external locus of control tend to be passive about environmental conditions, due to the belief that factors outside themselves cause the events that are experienced. In the case of homesickness, persons who have an external locus of control orientation tend to assume that no matter how much effort is made, it will not produce any improvement of the situation. This condition leads individuals to dissolve into negative emotions that interfere with proper functioning. Stevens (2002) also explains that individuals with an external locus of control tend to feel more intensely negative moods such as depression, anger, frustration, and aggression while experiencing a stressful situation.

\section{Social Support and Homesickness}

According to Hossein and Faramarz (2014), a student with strong social support tends not to have profound homesickness, whereas those who do not receive social support from their new environment are more vulnerable to homesickness.

Sarafino (2008) explains that social support can be given in several ways: emotional support, appreciation support, instrumental support, information support, and social network support. Emotional support is expressed through positive feelings that are manifested in empathy, attention, and concern for other individuals. It can lead to feelings of comfort, of being involved, and being loved when experiencing stress. Appreciation support occurs through expressions, rewards, or positive judgments of individuals, encouragement to advance and fostering of enthusiasm, as well as a favorable comparison with others. It focuses on the expression of a positive assessment of individuals and acceptance of the person. It leads to feelings in the individual that he is valuable, capable, and meaningful. Instrumental support can be realized through direct assistance, such as providing funds or assistance in the form of real actions or objects. Information support can be through activities such as giving advice or suggestions, directing, giving feedback on what was done. The social network support describes friendly relationships that allow individuals to spend time together, provide a sense of attachment and acceptance in groups, and carry out social activities together.

Hendrickson, Rosen, and Aune (2011) said that students who have more friendships, especially from the same city, show lower levels of homesickness and 
feel happy in a new environment. Social support is a source of emotional support and mentoring to deal with problems of daily life (Vieno, Santinello, Pastore, \& Perkins, 2007). Peers play a significant role in the growth of adolescents, because they can provide a safe place to express opinions, acknowledge weaknesses, and seek to solve problems (Papalia, Olds, \& Fieldman, 2009).

Social support from peers in a new environment can change an individual's perception of a stressor into something that can be dealt with and resolved, slowly reducing the intensity of homesickness so that the person can function well in everyday life. Social support can be obtained from the individuals or communities around one, which is needed during difficult times such as homesickness. It can also work as a barrier to adverse effects arising from various pressures (Sarafino, 2002).

Social supports can be emotional, appreciation (offering enthusiasm and confidence that the person can cope with challenging situations), instrumental (helping to do things), information (giving advice and suggestions), as well as networking (involving individuals in becoming part of a social group that has an impact on one's sense of acceptance, warmth, and understanding). On the other hand, people who lack social support are likely to react negatively to life's problems (Lahey, 2007). The feeling of being supported by the environment makes things easier, especially while a person is facing stressful events. Hendrickson, Rosen, and Aune (2011) show that friends have a role in helping students adapt better, reduce their homesickness, and make experiences in new environments more positive. Friendship provides assistance during transition periods.

The numerous studies on this issue mainly revolve around college students, but the present case study was being carried out with adolescents between ages 11 and 13, at a boarding school. Based on the literature review, we proposed these hypotheses: (a) an internal locus of control correlates negatively with homesickness; (b) social support correlates negatively with homesickness; (c) emotional support correlates negatively with homesickness; (d) appreciation support correlates negatively with homesickness; (e) instrumental support correlates negatively with homesickness; (f) information support correlates negatively with homesickness; and (g) social network support correlates negatively with homesickness.

\section{Method}

\section{Participants and Procedure}

The participants were first-year students of Boarding school is a place for students to learn until a specified time limit has been reached. This study used a list of questions that was prepared to be answered by the respondent. The questions are quite detailed and complete, and answer choices are provided. Participants were asked to fill in the questionnaire based on facts about themselves. Two hundred and seventy-five questionnaires were distributed and two hundred and twenty-six questionnaires returned with complete answers. The response rate was $82 \%$. Most of the participants were 12 years old (168 participants or $74.3 \%)$ and female (120 participants or $53.1 \%)$. The data are presented in Table 1. 
Table 1

Participants' characteristics

\begin{tabular}{llcc}
\hline \multicolumn{1}{c}{ Characteristics } & \multicolumn{1}{c}{ Profile } & Number & Percent \\
\hline \multirow{2}{*}{ Age } & 11 years old & 8 & 3.5 \\
& 12 years old & 168 & 74.3 \\
\multirow{3}{*}{ Gender } & 13 years old & 50 & 22.1 \\
& Male & 106 & 46.9 \\
& Female & 120 & 53.1 \\
\hline
\end{tabular}

\section{Measures}

Data were obtained by means of a homesickness scale, a locus of control scale, and a social support scale.

Homesickness. We created a homesickness scale with five dimensions: longing to go home, loneliness, longing for friends, difficulty in adapting to the new environment, and thinking about home (Stroebe et al., 2002). In analyzing the value of longing for home, the MSA value ranged from 0.561 to 0.876 , and the loading factor ranges from 0.633 to 0.853 . The MSA value of loneliness ranged from 0.780 to 0.926 and the loading factor value ranged from 0.618 to 0.839 . In longing for friends, the MSA value ranged from 0.690 to 0.742 , and the loading factor value ranged from 0.839 to 0.870 . Regarding difficulty in adapting to the new environment, the MSA value ranged from 0.728 to 0.903 , and the value of the loading factor was 0.539 to 0.761 . Finally, in thinking about home, the MSA value ranged from 0.707 to 0.796 , and the value of the loading factor ranged from 0.689 to 0.800 . The reliability of the homesickness scale is 0.945 .

Locus of control. Rotter (1966) notes that the locus of control scale is divided into internal and external orientations. Internal orientation consists of two behavioral aspects (effort and capability) and external orientation of three aspects (fate, luck, and influence of others). Regarding effort, the MSA value in our study ranged from 0.503 to 0.826 , while the loading factor value ranged from 0.587 to 0.714 . Regarding capability, the MSA value ranged from 0.611 to 0.811 , while the value of the loading factor ranged from 0.623 to 0.785 .

For external orientation, the MSA value for the aspect of fate ranged from 0.649 to 0.705 , while the value of the loading factor ranged from 0.727 to 0.829 . In the aspect of luck, the MSA value ranged from 0.501 to 0.675 , while the loading factor value ranged from 0.694 to 0.772 . Regarding the influence of others, the MSA value ranged from 0.653 to 0.819 , and the value of the loading factor ranged from 0.571 to 0.739 . The reliability of the locus of control scale is 0.923 .

Social support. We arranged the social support scale based on five dimensions (Sarafino, 2002): emotional support, appreciation support, instrumental support, information support, and social network support. On the dimension of emotional support, the MSA value ranged from 0.640 to 0.870 , and the loading factor value ranged from 0.663 to 0.817 . In appreciation support, the MSA value ranged from 0.651 to 0.805 , and the value of the loading factor ranged from 0.565 to 0.759 . For instrumental support, the MSA value ranged from 0.669 to 0.790 and the factor 
loading value ranged from 0.662 to 0.833 . With regard to information support, the MSA value was 0.619 to 0.823 , and the value of the loading factor ranged from 0.525 to 0.781 . For social network support, the MSA value ranged from 0.681 to 0.881 , and the value of the loading factor ranged from 0.564 to 0.806 . The reliability of the social support scale is 0.948 .

\section{Results}

Pearson correlation was used to assess the linear association between homesickness on the one hand, and locus of control and social support on the other. Stepwise regression was used to explore the relationship between locus of control and social support for a person suffering from homesickness. In this way, we sought to determine whether the locus of control and social support can make a significant, unique contribution to the prediction of homesickness. The Pearson correlation analysis showed that locus of control and social support significantly correlated with homesickness. Emotional support, appreciation support, instrumental support, information support, and social network support also significantly correlated with homesickness. The results are presented in Table 2.

Table 2

Summary of Pearson correlations among variables

\begin{tabular}{lcccccccccc}
\hline \multicolumn{1}{c}{ Variables } & Mean & SD & $\mathbf{1}$ & $\mathbf{2}$ & $\mathbf{3}$ & $\mathbf{4}$ & $\mathbf{5}$ & $\mathbf{6}$ & $\mathbf{7}$ & $\mathbf{8}$ \\
\hline 1. Homesickness & 62.548 & 12.631 & 1 & & & & & & & \\
2. Locus of control & 61.327 & 10.201 & $-.209^{* *}$ & 1 & & & & & & \\
3. Social support & 68.623 & 12.818 & $-.400^{* *}$ & .112 & 1 & & & & & \\
4. Emotional & 15.734 & 3.834 & $-.376^{* *}$ & .077 & $.868^{* *}$ & 1 & & & & \\
5. Appreciation & 11.902 & 3.233 & $-.314^{* *}$ & .075 & $.783^{* *}$ & $.632^{* *}$ & 1 & & & \\
6. Instrumental & 10.433 & 2.157 & $-.202^{* *}$ & $.152^{*}$ & $.688^{* *}$ & $.457^{* *}$ & $.427^{* *}$ & 1 & & \\
7. Information & 13.969 & 2.776 & $-.294^{* *}$ & .065 & $.783^{* *}$ & $.601^{* *}$ & $.479^{* *}$ & $.481^{* *}$ & 1 & \\
8. Social network & 16.584 & 3.763 & $-.378^{* *}$ & .105 & $.877^{* *}$ & $.688^{* *}$ & $.567^{* *}$ & $.582^{* *}$ & $.630^{* *}$ & 1 \\
\hline
\end{tabular}

Note. ${ }^{* *} p<.01$

In order to find variables that contributed to homesickness, we also conducted a stepwise regression analysis. Based on the first step regression analysis, social support became a predictor of homesickness $(\beta=-.400, \mathrm{p}<0.01 ; \mathrm{F}=42.723, \mathrm{p}<$ $\left.0.01 ; \mathrm{R}^{2}=.160\right)$. In step 2 , locus of control was also a predictor of homesickness $\left(\beta=-.166, \mathrm{p}<0.01 ; \mathrm{F}=25.721, \mathrm{p}<0.01 ; \mathrm{R}^{2}=.027\right)$. The predictive value of both predictors increased $\left(\mathrm{R}^{2}=.187\right)$. The regression analysis showed that locus of control and social support were negative predictors of homesickness. Social support is a strong predictor of homesickness among first-year boarding-school students. The analysis yielded a value of $\mathrm{F}=25.721, \mathrm{p}<0.01$. We can stipulate that the regression equation is a good fit. The results are presented in Table 3. 
Table 3

Summary of stepwise regression analysis among variables

\begin{tabular}{lcccccc}
\hline \multicolumn{1}{c}{ Variables Predictor } & $\mathbf{B}$ & $\mathbf{S E ~ B}$ & $\mathbf{B}$ & $\mathbf{R}^{2}$ & $\Delta \mathbf{R}^{2}$ & $\mathbf{F}$ \\
\hline Step 1 & & & & & & \\
Constant & 89.612 & 4.212 & -.400 & & & $42.723^{* *}$ \\
Social support & -.394 & .060 & & .160 & .160 & \\
Step 2 & & & & & & \\
Constant & 100.970 & 5.872 & & & & $25.721^{* *}$ \\
Social support & -.376 & .075 & -.382 & .187 & .027 & \\
Locus of control & -.206 & .060 & -.166 & & & \\
\hline
\end{tabular}

Note. ${ }^{* *} p<.01$

Table 4

Results for stepwise regression analysis based on social support

\begin{tabular}{lcccccc}
\hline \multicolumn{1}{c}{ Variables } & B & SE B & $\boldsymbol{\beta}$ & $\mathbf{R}^{2}$ & $\Delta \mathbf{R}^{2}$ & $\mathbf{F}$ \\
\hline Step 1 & & & & & & \\
Constant & 83.595 & 3.530 & & .143 & .143 & $37.371^{* *}$ \\
social network & -1.269 & .208 & $-.378^{* *}$ & & & \\
Step 2 & & & & & & \\
Constant & 86.577 & 3.666 & & .169 & .026 & $22.607^{* *}$ \\
social network & -.760 & .283 & $-.226^{* *}$ & & & \\
emotional support & -.727 & .277 & $-.221^{* *}$ & & & \\
\hline
\end{tabular}

Note. ${ }^{* *} p<.01$

Stepwise regression analysis was also conducted to find out the determinant of homesickness based on dimensions of social support. In step 1, it showed that social network became a predictor of homesickness $(\beta=-.378, \mathrm{p}<0.01 ; \mathrm{F}=37.371$, $\left.\mathrm{p}<0.01 ; \mathrm{R}^{2}=.143\right)$. In step 2 , emotional support was also a predictor of homesickness $\left(\beta=-.221, \mathrm{p}<0.01 ; \mathrm{F}=22.607, \mathrm{p}<0.01 ; \mathrm{R}^{2}=.026\right)$. The social network is a strong predictor of homesickness among first-year boarding-school students. The results are seen in Table 4.

\section{Discussion}

This study aimed to find out the role of locus of control and social support in homesickness among first-year boarding-school students. Based on statistical analysis, we found that locus of control and social support negatively influenced homesickness. Students with an internal locus of control tended to be less homesick. Bahrainian and Yari (2013) found that students with an internal locus of control have good adaptability in a transitioning environment. 
Solmuu (2004) argued that different behaviors are associated with individuals with an internal locus of control compared to those with an external locus of control, with regards to environmental changes. People with an internal locus of control are more enthusiastic and responsive in a new environment. When facing difficulties or dissatisfactions, they tend to make efforts to tackle these situations.

Alternatively, individuals with external locus control tend to have pessimistic attitudes, which makes it difficult for them to solve problems (Solmuu, 2004). This usually leads to homesickness. The various explanations above are in line with the results of research by Jain and Singh (2015), which found that individuals with an internal locus of control adjusted well in various aspects of life and in a new environment.

Aside from their ability to adapt to environmental changes, those with an internal locus of control have good psychological intuition, as they can control various conflicts and uneasiness that come their way. Individuals with an external locus of control, on the other hand, experience anxiety, stress, and depression more often, owing to their inability to control what life throws against them (Ashby, Kottman, \& Drapper, 2002).

April, Dharani, and Peters (2012) found that students with an external locus of control experienced greater stress than those with an internal locus of control, supporting the explanations outlined above. Similarly, Shojaee and French (2014) showed that individuals with an internal locus of control tended to possess good mental health, making it possible for them to avoid stress. Positive psychological well-being could help individuals to avoid various negative emotions associated with homesickness.

Urani, Miller, Johnson, and Petzel (2003) showed that persons who experience homesickness are influenced by limited social support from their environment. Students who got social support from their peers in the form of attention, encouragement, and material assistance tended to feel more comfortable and calm. The feeling of being supported by the environment will make things easier for a student, especially while facing stressful events. Friends have roles in helping students adapt better, reduce their homesickness, and make experiences in new environments more positive.

According to Sarafino (2002), social support is one of the paramount and essential elements in life capable of eliminating the adverse effects arising from a change in environment. Nejad, Pak, and Zarghar (2013) explained that most individuals who experience displacement are faced with challenges associated with homesickness in their first year. Anxiety, loneliness, discomfort, and rejection are some common conditions that tend to appear. However, adequate support from the environment can change these individuals' negative perspective regarding the new environment (Sarafino, 2006).

The present study found that a social network is a strong predictor of homesickness among first-year boarding-school students. The social network is a personal network such as friends connected by interpersonal relationships. Friendship is an essential component for individuals in satisfying deep personal and emotional needs (Hendrickson, Rosen, \& Aune, 2011). Friendship plays a vital role in life and friends are a source of affection and cognitive that can improve well-being (Okoda, 2012). The social network will improve the quality of friendship, attention, and empathy 
among friends. Individuals with a high empathy level care about their friends and are able to anticipate the negative impact of their behavior towards others (Zulkarnain, Siregar, Yusuf, \& Wahyuni, 2019). This attention and empathy can strengthen the friendship and maintain its quality, ultimately reducing homesickness.

\section{Conclusion}

The purpose of this study was to better understand students' homesickness in their transition from home to dormitory life. The findings have important implications for academic advisers, parents, and students. Feelings of separation from friends and family are normal phenomena experienced by most first-year students. Boys and girls can experience homesickness in various settings such as at camp or in boarding school.

Social support plays a significant role in reducing homesickness and increasing student well-being. Social support from friends in the new environment can change student perception of a stressor into something that can be dealt with and resolved. Students often need social support from other people, such as family, friends, and neighbors, in dealing with challenging situations. Social support has a role in helping students adapt better and make experiences in new environments more positive. This study also found that students with an internal locus of control could control difficult situations in the transition from home to school because of their belief that they can control all events that occur in life. These beliefs encourage individuals to strive to reduce negative emotions and psychological conditions that are not comfortable. Some suggestions that can be given to students to reduce homesickness include involving themselves in extracurricular activities provided by the boarding school, to avoid thinking about home. This establishes socialization with people around the boarding school and activities or hobbies can build a positive mood in boarding schools.

\section{Limitations}

This study has some limitations. First-year boarding-school students were the main subjects, but it can be debated whether first-year boarding-school students in other places with a different culture face the same problems that result in homesickness. Therefore, future studies could investigate first-year boarding-school students from various cultures, discussing differences in homesickness. Furthermore, this study only uses cross-sectional study data and does not investigate interactions of different variables over time; therefore, it is not possible to reach any conclusions about cause and effect among items based on participants' responses. A longitudinal study is needed to confirm the findings reached by this study. Another limitation is that some relevant data may not be available because of the nature of the data or because it would violate confidentiality.

\section{Acknowledgments}

We want to thank all the first-year students and school administrators for allowing us to do this research. We also thank the Faculty of Psychology of the Universitas of Sumatera Utara for facilitating our work. 


\section{References}

April, K.A., Dharani, B., \& Peters, K. (2012). Impact of locus of control expectancy on level of well-being. Review of European Studies, 4(2), 124-136. http://doi: 10.5539/res.v4n2p124.

Ashby, J., Kottman, T., \& Draper, K. (2002). Social interest and locus of control: Relationships and implications. Journal of Individual Psychology, 58(1), 52-61.

Bahrainian, A., \& Yari, M. (2014). The relationship between locus of control and social support with social adjustment in vocational school's trainees in Tehran. Journal of Applied Environmental and Biological Sciences, 4(4)271-277.

Bonanno, G.A. (2001). New direction in bereavement research and theory. American Behavioral Science, 44(5), 718-726. http://doi: 10.1177/00027640121956458

Borg, C., \& Cefai, C. (2014). Stress, health and coping among international students at the University of Malta. Centre for Resilience and Socio Emotional Health: University of Malta, Malta.

Buote, V.M., Pancer, S.M., Pratt, M.W., Adams, G., Birnie-Lefcovitch, S., Polivy, J., \& Wintre, M.G. (2007). The importance of friends: Friendship and adjustment among 1st-year university students. Journal of Adolescent Research, 22(6), 665-689. http:// doi:10.1177/0743558407306344

Feist, J., \& Feist, G.J. (2010). Theories of Personality (10th ed.). Jakarta: Salemba Humanika.

Fisher, S., Frazer, N., \& Murray, K. (1986). Homesickness and health in boarding school children. Journal of Environmental Psychology, 6(1),35-47.http://doi: 10.1016/S0272-4944(86)80033-0

Hendrickson, B., Rosen, D., \& Aune, R.K. (2011). An analysis of friendship networks, social connectedness, homesickness, and satisfaction levels of international students. International Journal of Intercultural Relations, 35(3), 281-295. http:// doi:10.1016/j.ijintrel.2010.08.001.

Hurlock, E.B. (1999). Developmental psychology: An approach throughout the space of life. (5th ed.). Jakarta: Erlangga.

Jain, M., \& Singh, S. (2015). Locus of control and its relationship with mental health and adjustment among adolescent females. Journal of Mental Health and Human Behavior, 20(1), 16-21. http:// doi:10.4103/0971-8990.164803

Lefcourt, H.M. (1976). Locus of control and the response to aversive events. Canadian Psychological Review, 17(3), 202-209. http://doi:10.1037/h0077090

Nejad, S.B., Pak, S., \& Zarghar, Y. (2013). Effectiveness of social skills training in homesickness, social intelligence and interpersonal sensitivity in female university students resident in dormitory. International Journal of Psychology and Behavioral Research, 2(3), 168-175.

Okada, R. (2012). Friendship motivation, aggression, and self-esteem in Japanese undergraduate students. Psychology, 3(1), 7-11. http://doi:10.4236/psych.2012.31002

Papalia, D.E., Olds. S.W., \& Feldman R. D. (2007). Human development (10th ed.). New York: McGraw Hill Companies.

Poyrazli, S., \& Lopez, M. (2007). An exploratory study of perceived discrimination and homesickness: A comparison of international students and American students. The Journal of Psychology: Interdisciplinary and Applied, 141(3), 263-280. http://doi:10.3200/JRLP.141.3.263280

Rajapaksa, S., \& Dundes, L. (2003). It's a long way home: International student adjustment to living in the United States. College Student Retention, 4(1), 15-28. https://doi:10.2190/5HCY-U2Q9-KVGL-8M3K

Rotter, J.B. (1966). Generalized expectancies for internal versus external control of reinforcement. Psychological Monographs, 80(1), 1-28. http://doi:10.1037/h0092976

Sarafino, E.P. (2002). Health psychology: Biopsychological interactions (2nd ed.). New York: John Wiley \& Sons.

Sarafino, E. P. (2006). Health psychology: Biopsychosocial interactions. (5th ed). New York: John Wiley \& Sons. 
Shojaee, M., \& French, C. (2014). The relationship between mental health components and locus of control in youth. Scientific Research and Academic Publisher, 5(8), 966-978. https:// doi:10.4236/psych.2014.58107

Solmuu, T. (2004). Working life, locus of control, and five-factor personality model. Turk Psikoloji Bulteni, 10(1), 196-205.

Stroebe, M., Van Vliet, T., Hewstone, M., \& Willis, H. (2002). Homesickness among students in two cultures: Antecedents and consequences. British Journal of Psychology, 93(2), 147-168. https://doi:10.1348/000712602162508

Tartakovsky, E. (2007). A longitudinal study of acculturative stress and homesickness: Highschool adolescents immigrating from Russia and Ukraine to Israel without parents. Social Psychiatry Epidemiology, 42(6), 485-494. http://doi:10.1007/s00127-007-0184-1

Thurber, C. (1999). The phenomenology of homesickness in boys. Journal of Abnormal Child Psychology, 27(2),125-139. http://doi:10.1023/A:1021911514768

Tognoli, J. (2003). Homesickness, place attachment, and transition among residential college students. Journal of College Student Psychotherapy, 18(1), 35-47. http://dx.doi.org/10.1300/J035v18n01_04

Tilburg, M., \& Vingerhoets, A. (2005). Psychological aspect of geographical moves: Homesickness and acculturation stress. Amsterdam Academic Archive. Amsterdam University Press. https://doi.org/10.5117/9053568603

Urani, M., Miller, S., Johnson, J., \& Petzel, T. (2003). Homesickness in socially anxious first year college students. College Student Journal, 37(3), 392-390.

Wade, C., \& Tavris, C. (2008). Psychology. Jakarta: Erlangga.

Ward, C., \& Kennedy, A. (1993). Where's the culture in cross-cultural transition? Comparative studies of sojourner adjustment. Journal of Cross-cultural Psychology, 24, 221-249. http://doi:10.1177/0022022193242006

Watt, S.E., \& Badger, A.J. (2009). Effects of social belonging on homesickness: An application of the belongingness hypothesis. Personality and Social Psychology Bulletin, 35(4), 516-530. http://doi:10.1177/0146167208329695.

Zulkarnain, Siregar, A.R., Yusuf, E.A., \& Wahyuni, P. (2019). Bullying at school and impact of empathy training. Journal of Social Sciences Research, 5(1), 117-120. https:// doi:10.32861/jssr.51.117.120

Original manuscript received September 07, 2018

Revised manuscript accepted March 04, 2019

First published online June 15, 2019

To cite this article: Zulkarnain, Z., Daulay, D.A., Yusuf, E.A., Yasmin, M. (2019). Homesickness, Locus of Control and Social Support among First-Year Boarding-School Students. Psychology in Russia: State of the Art, 12(2), 134-145. DOI: 10.11621/pir.2019.0210 